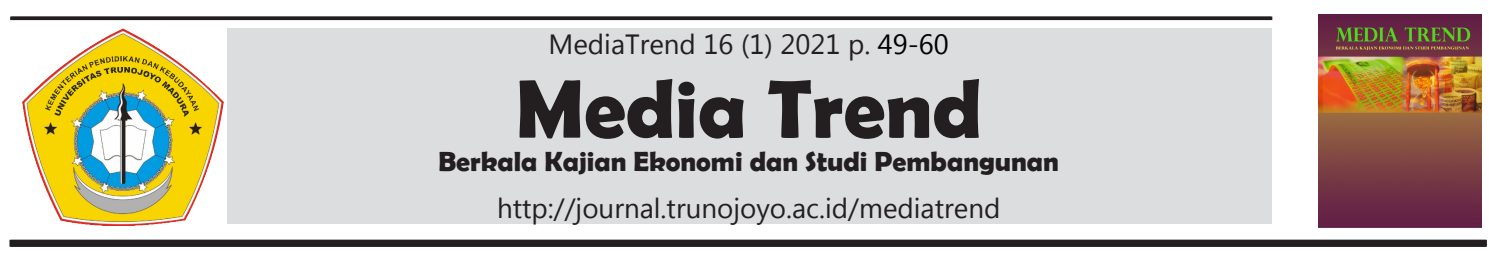

Government Budget, and Health Insurance for Public Health in East Java Province

\title{
Sony Kristiyanto
}

Wijaya Kusuma University

\section{Article Information}

History of article:

Received January 2021

Approved February 2021

Published March

2021

\begin{abstract}
A B S T R A C T
One of the conditions needed for development to be carried out properly is the condition of a healthy community. Without a healthy community, development in one area cannot be done well. Health itself is more a public good than a private good, so in this case government intervention is absolutely necessary. This research tries to look at several factors which are predicted to be able to influence the condition of public health. Some of these factors are the availability of infrastructure in the health sector, the government budget and public participation in health insurance issued by the government. Using data between 2017 and 2019 in 38 districts in East Java Province, it was found that only the public participation variable in health insurance issued by the government had a positive and significant impact, while the other variables did not affect the health condition of the community. The behavior of people in Indonesia who tend to register for health insurance if they have experienced health problems is one indication of a positive relationship between public health conditions and the number of participants in government health insurance.
\end{abstract}

Keywords: Health Economics, Government Spending, Infrastructure, Health Insurance.

JEL Classification Code: H5, I15, O18, 


\section{INTRODUCTION}

In essence, the goal of development carried out in Indonesia is the development of the Indonesian people as a whole. This means that development does not only include efforts to improve human welfare from a material side alone, but also must be able to develop humans themselves (Sattler et al., 2018). One of the things that is able to make this happen is through development in the health sector. By developing the health sector, it is hoped that it will produce healthy public output which will ultimately be able to support national development as a whole (Joshi et al., 2020).

The administration of President Joko Widodo, both in the first period and in the second period, focused on infrastructure development in all aspects, both physical and non-physical infrastructure. The infrastructure built includes infrastructure in the health sector. The development of physical health infrastructure includes the construction of hospitals, both general and special hospitals, as well as the construction of other health facilities such as the construction of puskesmas, provision of posyandu services that are spread out to village levels. Meanwhile, in terms of non-physical infrastructure development, the government has increased the quantity and quality of medical personnel (doctors, ranging from general practitioners, specialists to specialist consultants) and paramedics (nurses, midwives, pharmacists, nutritionists and other paramedics) (Aghapour et al., 2019). The availability of infrastructure both physical and non-physical infrastructure is very important, considering that the development of the health sector will not be possible if the infrastructure is not available (Tambo et al., 2019).

Ingeneral, the development of health infrastructure is still centered on the island of Java. This condition is not surprising considering that until now, the island of Java is still the center of activity in Indonesia. Nearly 80 percent of both economic activities and other activities in Indonesia are on the island of Java. However, infrastructure development, both public infrastructure and infrastructure in the health sector in various cities outside the island of Java, is still carried out in accordance with the proportions of the cities concerned. 


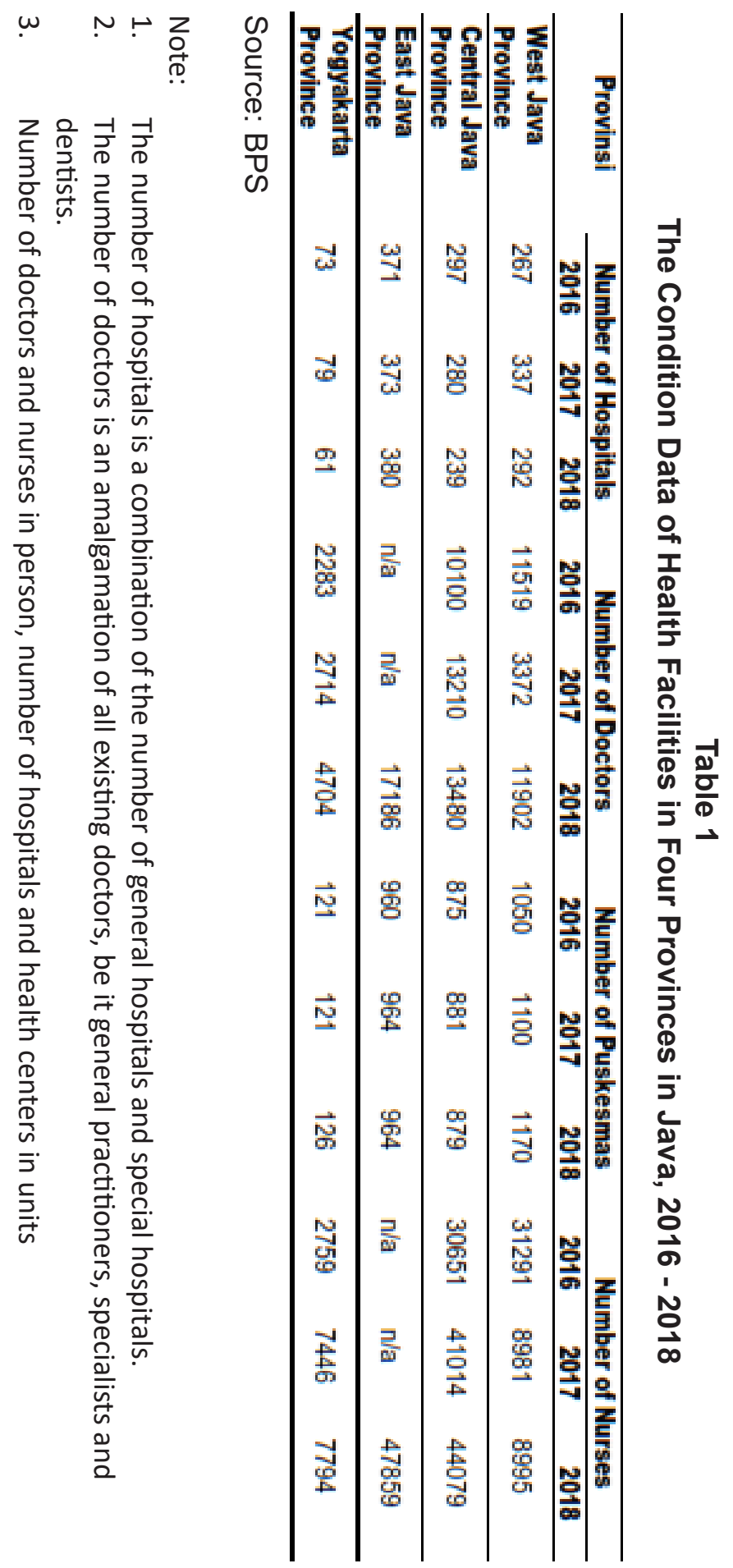


Observing the data released by BPS regarding the number of hospitals, doctors, health centers, and nursing personnelfrom 2016 to 2018 is an interesting thing. The four provinces on the island of Java, namely West Java Province, Central Java Province, Jogjakarta Special Region Province and East Java Province, display quite unique data. Although the government has made claims that it has built infrastructure in the health sector, certain data shows otherwise. The number of hospitals in West Java Province has actually decreased from 2017 to 2018. Likewise, Central Java Province and the Special Region of Jogjakarta Province. Likewise for the number of doctors and the number of nurses. Both of these things experienced fluctuating conditions that occurred in almost all provinces. The number of puskesmas has remained relatively unchanged, because the policy of one sub-district for one puskesmas has been implemented in almost all regency cities on the island of Java. The number of hospitals that experienced a decline was more due to the fact that private hospitals merged with other larger hospitals or there were several hospitals that had to be closed due to not meeting basic hospital service standards.

One indicator of the success or failure of development in the health sector is the public health condition itself. The easiest thing is how many people experience complaints about their health (Cooper \& Wardropper, 2021). The higher the number of people who still experience complaints of illness, the health development in that area is still not being carried out optimally. The development of health infrastructure primarily by providing sophisticated medical equipment and opening public access to the use of these medical equipment (Schünemann et al., 2017). By providing these medical devices, the community will be helped more quickly if they experience health problems.

Another indicator to assess the success or failure of development in the health sector is by looking at life expectancy. The higher the life expectancy in one area, it can be said that the development of the health sector in that region has been running optimally. A high life expectancy reflects that productivity in the country is also high. High productivity will certainly correlate with a higher level of the economy.

Table 2

Percentage of Population Experiencing Health Complaints in 2017 and 2018

Source: BPS

\begin{tabular}{|c|c|c|}
\hline \multirow{2}{*}{ Province } & \multicolumn{2}{|c|}{ Year } \\
\hline & 2017 & 2018 \\
\hline East Java & 34,48 & 33.80 \\
\hline West Java & 65.26 & 51.18 \\
\hline Yogyakarta & 52.74 & 50.34 \\
\hline
\end{tabular}

The table regarding the percentage of the population experiencing health complaints in three provinces in the island of Java indicates that the development of the health sector in Indonesia is still not optimal. West Java Province is a province with the lowest level of health compared to other provinces on the island of Java. More than half of the population experienced health complaints between 2017 and 2018. In contrast, East Java Province was the best province when viewed from the number of residents who experienced health complaints for the period 2017 and 2018. In the 2017 and 2018 periods, the number of people who experienced health complaints health problems were only recorded at less than 40 percent. 
Source: BPS

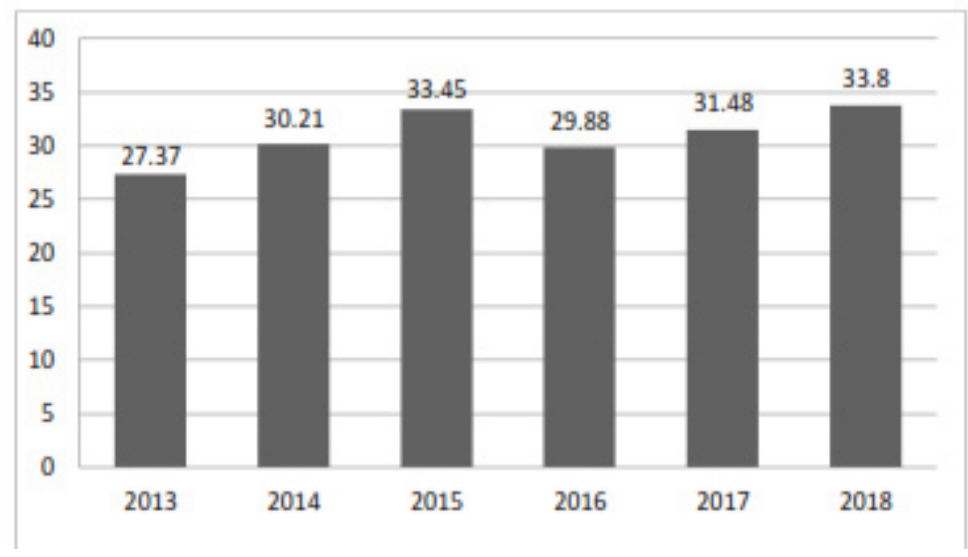

Figure 1

\section{Percentage of Population with Health Complaints in East Java Province}

The number of residents in East Java Province who experience health complaints tends to be constant, between 27 percent and the highest at 33.8 percent. Compared to other provinces on the island of Java, the health condition in East Java Province is the best. If a trend line is drawn from 2013 to 2018, the number of people in East Java Province tends to increase from year to year.

Looking at the explanation that has been conveyed, this paper tries to look more comprehensively about the condition of infrastructure development in East Java Province. The percentage of population experiencing health complaints continues to increase, but on the other hand, the number of doctors and nurses in East Java Province has also increased. Likewise, the number of hospitals also experienced an increase from the previous years. With the increase in hospitals, health centers and medical personnel, the number of people who experience health complaints should be able to be reduced or at least reduced.

The government itself, in order to carry out its obligations to help nourish the nation, has provided several steps. Generally, these government measures are still not comprehensive and more political in nature when compared to other countries that have provided health protection for citizens (Abbott \& Jones, 2020). The most obvious step is to issue a policy regarding BPJSHealth, whereevery Indonesiancitizen is required to have a BPJSHealth card. BPJS itself briefly applies the concept of mutual cooperation insurance, where participants will be charged a monthly fee according to the class or group chosen. The form of mutual cooperation from BPJS lies in the awareness of the public to pay the BPJS dues. Indirectly, if people continue to pay dues to BPJS even though they don't use them, then they have helped people who need medical assistance and use services covered by BPJS. In its journey, BPJS was transformed into a Healthy Indonesia Card (KIS), but with the same concepts and rules.

Research conducted by Sanjaya (2007)onhealth costs in Indonesiahas come to the conclusion that most Indonesians do not own or do not use these health facilities and prefer to use their personal money to pay for health complaints. Furthermore, Sanjaya (2007) also reveals that the costs incurred by people living in urban areas will be higher when compared to people living in suburban areas. However, for people living in suburban areas, if they want to get more comprehensive health services, they have to pay additional costs for transportation and other costs. 
Giang (2008) examined health insurance in Vietnam. Vietnam is one of the countries experiencing the transition from being a socialist country to a country that is more open. Regarding the health of its citizens, Vietnam has a social safety net in the form of health insurance for its citizens. Research conducted by Giang (2008) proves that a good insurance scheme is proven to have a significant positive contribution. Like the problems faced by developing countries, Vietnam is experiencing difficulties in implementing the public health insurance scheme, especially with regard to financial and administrative problems that have not been properly organized.

Australia is a country that requires its citizens to have non-government health insurance. Researchconducted by Connelly and Brown (2008) reveals this. Furthermore, the study revealed that the Australian government will provide additional fines if people deliberately buy insurance at an advanced age where at an advanced age they have a higher risk of disease when compared to younger ages.

This paper will review about how the public health condition in East Java Province and several factors that are thought to be able to influence it. The public health condition in East Java Province in this study will be represented by the percentage of health complaints by the public. The initial part of this paper also reveals that the government is aggressively developing infrastructure, including health infrastructure. Thispaperalsotriestolinkthis, namely how the health infrastructure, both physical and non-physical infrastructure, is related to the health conditions of the people in East Java Province. The physical infrastructure in this study will be proxied by the number of hospitals and puskesmas, while the non-physical infrastructure will be represented by the number of doctors. The government variable in this case is represented by the government spending variable in the health sector.

The problem to be raised in this research is whether the availability of basic health infrastructure, be it physical infrastructure (number of hospitals and healthcenters)ornon-physicalinfrastructure (number of doctors) and government spending in the health sector is able to partially affect the health conditions of the people in East Java Province. as well as simultaneously. This study aims to determine the relationship between the availability of basic health infrastructure, both physical and non-physical, as well as the government's participation in influencing the health conditions of the people in East Java Province. The author hopes that this research will be especially useful in broadening the horizons of health economics knowledge. In addition, the authors also hope that this paper can be a reference for further studies that have similarities in the field of this research.

\section{METHODOLOGY}

This research is a quantitative study with a panel data approach. The data used in this study is secondary data that has been published by the Central Statistics Agency (BPS). All data used in this study refer to data from the Province of East Java in Figures released by BPS starting from 2018, 2019 and 2020. These data can be downloaded online via the BPS website. Health sector government expenditure budget data uses data issued by the Directorate General of Central and Regional Financial Balancing, Ministry of Finance of the Republic of Indonesia. Similar to the data obtained from BPS, this health sector government budget data can also be obtained by downloading via the website page directly.

The data referred to in this study are: the percentage of people who experience health complaints, data on the number of BPJS participants, data on government expenditure budgets in the 
banking sector, number of doctors, number of hospitals and number of health centers. To complement the secondary data obtained from BPS and the Ministry of Finance, this study also uses data with the literature study method or with standardized theories and research journals that have been conducted previously.

$Y_{i t}=\alpha+\beta_{1} X_{1 i t}+\beta_{2} \log X_{2 i t}+\beta_{3} \log X_{3 i t}+$ $\beta_{4} \log X_{4 i t}+\beta_{5} \log X 5 i t+\varepsilon i t$

Where:

$\mathrm{Y}=$ Percentage of the number of people who experience complaints of illness

$\mathrm{X} 1$ it $=$ Percentage of total population who have BPJS Kesehatan

X2it = Number of doctors, in person.

X3it $=$ Number of hospitals, in units.

X4it = Number of puskesmas, in units.

$\mathrm{X} 5$ it = Health sector government expenditure budget, in rupiah units.

Some econometric literature states that to find out which Common Effect Model (CEM) or Fixed Effect Model (FEM) which will be selected for data estimation can be done by using the F-Test. PLS is a restricted model where the model applies the same intercept to all individuals. As is well known, sometimes the assumption that each unit cross section has the same behavior tends to beunrealistic because it is possible that each unit cross section has a different behavior (Bettin \& Sacchi, 2020). The steps taken to carry out this test are to use the Chow Test. The restricted F Test step is carried out in a Fixed Effect Model condition. If in the Chow test it is decided that the Fixed Effect Model is better, then proceed with the Haussman test to see if the Fixed Effect Model or Random Effect Model is better used (Agénor, 2008).

If it is known that the unrestricted model is better used than the restricted model, then the next step is to see whether the unrestricted model follows the random effect or the fixed effect with the Hausman Test. If the Haussman test is found to be statistically significant, then the model chosen is the fixed effect model, on the other hand, if the Hussman test is not statistically significant, the random effect model is chosen.

If the model selection test using both the Chow Test and the Haussman Test shows the same results, no further testing is needed. However, if different results are found in the Chow Test and Haussman Test, it will proceed to the next test, namely the Lagrange Multiplier Test (LM - Test). The LM Test is used to decide whether the Random Effect Model or the Common Effect Model is the most appropriate to be used in this study. If the LM Test is known to be statistically significant, the model chosen is the Random Effect Model, and vice versa.

The use of parameter testing in the framework of the panel data model is still being debated today. There are two opinions which suggest that in panel data construction, parameter testing is still needed while other opinions say otherwise. In this study, the classical assumption test (multicollinearity, heteroscedasticity, and autocorrelation) was not carried out considering the model that was tried to be built in this study was a panel data model. Panel data there is no need for classical assumption testing as is done in modeling using time series or cross section data only, because parameter estimation using either the randomeffect or the fixed effect approach does not require data to be used (Gupta \& Barman, 2010). fulfilling classical assumptions such as freeing these data from multicollinearity, heteroscedasticity and autocorrelation problems.

Several other literatures also emphasize that panel data which is a combination of time series data and 
cross section data will cover each other's weaknesses. Time series data will be very susceptible to autocorrelation problems and this can be minimized by including cross section elements. Likewise, cross section data has a high probability of being exposed to heteroscedasticity. Heteroscedasticity problems that commonly arise in cross section data are eliminated by entering time series data (Kruse et al., 2012). One of the advantages of using panel data is that data is more informative than using cross section data or time series data. The use of panel data also makes it possible for researchers to study in more detail the behavior of each individual in the study. With the advantages possessed by panel data, the implication when using panel data in research is that there is no need for classical assumption testing (Fanti \& Gori, 2011).

\section{RESULTS AND DISCUSSION}

The model in this study with panel data, the first thing to do is to choose whether the Common Effect Model, Fixed Effect Model or Random Effect Model is the most appropriate to be used in this study. For that, the first step that must be taken is to do the Chow Test and the Haussman Test. The results of these tests are as follows:

Table 3

Chow Test Results

\begin{tabular}{llll}
\hline Effect Test & Statistic & df & Prob \\
\hline Cross Section Fixed & 3.707857 & $(37,71)$ & 0.000 \\
\hline Cross Section Chi Square & 122.638319 & 37 & 0.000 \\
\hline
\end{tabular}

The results obtained from the Chow Test indicate that between modeling with the Common Effect Model and Fixed Effect Model approaches, the Fixed Effect Model is preferred. This can be seen from the Chow Test probability value of 0.000 , which means it is statistically significant with a confidence level of 95 percent. After knowing that the Fixed Effect Model is better than the Common Effect Model, the next step is to compare the Fixed Effect Model with the Random Effect Model using the Haussman Test. The results of the Haussman Test are as follows:

Table 4

Hausman Test Results

\begin{tabular}{rllc}
\hline Test Summary & Chi-Sq Statistic & Chi-Sq df & Prob \\
\hline Cross Section Random & 3.185951 & 5 & 0.6713 \\
\hline
\end{tabular}

The results of the Haussman test show that it is not statistically significant, where the probability value is still higher than the value of the degree of error of five percent. This indicates that the Random Effect Model is better than the Fixed
Effect Model. Because the results of the Chow test and Haussman Test show different results, it is necessary to have an LM - Test to determine which model should be used in this study. The results of the LM - Test are as follows: 
Table 5

Lagrange Multiplier Test

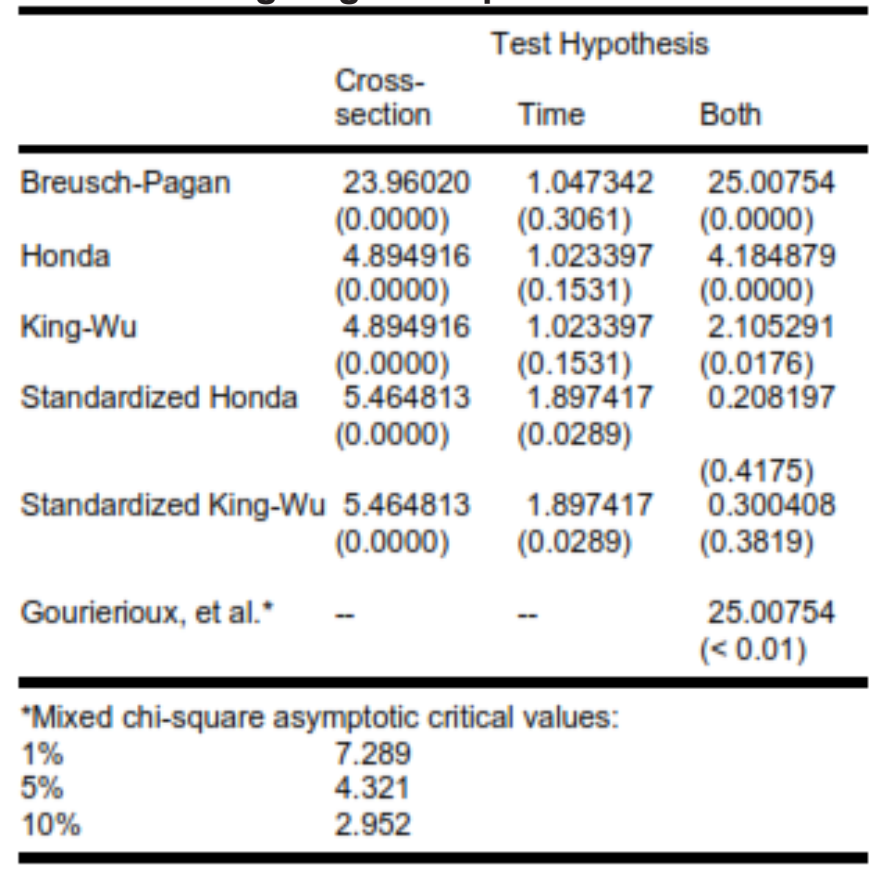

The results of LM - Test calculations this study. Furthermore, the following will show that the Random Effect Model is the display the results of the regression using most suitable panel data model for use in the Random Effect Model approach:

\section{Table 6}

\section{Random Effect Model}

\begin{tabular}{lll}
\hline Variable & Coefficient & Prob. \\
\hline $\mathrm{C}$ & 36.07843 & 0.4718 \\
\hline $\mathrm{X} 1$ & 0.334665 & 0.0006 \\
\hline $\mathrm{LOG}(\mathrm{X} 2)$ & 1.507376 & 0.2096 \\
\hline $\mathrm{LOG}(\mathrm{X} 3)$ & -0.503957 & 0.6540 \\
\hline $\mathrm{LOG}(\mathrm{X} 4)$ & -1.345667 & 0.4423 \\
\hline $\mathrm{LOG}(\mathrm{X} 5)$ & -0.554027 & 0.7919 \\
\hline
\end{tabular}

After getting the regression line with line. The statistical test consists of theT the Random Effect Model, the next step is to test and $F$ test as well as seeing the perform a statistical test on the regression coefficient of determination in this study.

Table 7

T - Statistic

\begin{tabular}{lll}
\hline \multicolumn{1}{c}{ Variable } & \multicolumn{1}{c}{ Prob } & \multicolumn{1}{c}{ Remark } \\
\hline constant & 0.4718 & Not Significant \\
\hline X1 & 0.0006 & Significant \\
\hline LOG $(\mathbf{X 2})$ & 0.2096 & Not Significant \\
\hline LOG $(\mathbf{X 3})$ & 0.6540 & Not Significant \\
\hline LOG $(\mathbf{X 4})$ & 0.4423 & Not Significant \\
\hline LOG $(\mathbf{X 5})$ & 0.7919 & Not Significant \\
\hline
\end{tabular}


Based on the table regarding the results of the partial statistical test that has been shown, it can be seen that only the variable percentage of the population who has a BPJS card is statistically significant. Apart from these variables were not statistically significant. The percentage of the population who has a BPJS is significant with a positive correlation, so that if the number of people who have a BPJS card increases by one percent, it will be followed by the percentage of the population experiencing illness complaints will increase by 3.5 percent.

From this calculation it is also recognized that the statistical $F$ value is 3.343 which is higher than the $F$ table value of 2.19 which means that together, all the variables offered in this study are able to influence the percentage of the population who experience illness complaints. The coefficient of determination in this study amounted to 13.37 percent. This means that the combination of the independent variables offered in this study covers 13.37 percent of all combinations in the real world. The remaining 86.63 percent is influenced by other variables outside the variables in this study.

This research reveals an interesting thing, that health insurance is very important for society. By having health insurance, be it insurance issued by the government or private health insurance, so if the community has a problem with their health, the community does not need to reduce their assets to finance their health. What is interesting in this study is that there is a positive correlation between health insurance ownership and health complaints from the public. Theoretically, the correlational relationship between the two variables is negative, so if the number of insurance participants increases, it will be followed by a decrease in the number of people who experience complaints in health. However, this study shows the opposite.

The positive correlation between the number of people who take part in health insurance issued by the government is more due to the condition of the Indonesian people themselves. Indonesian society is still low in literacy regarding health insurance, so generally people will register to become members of the BPJS if they feel they have problems with their health. Community behavior like this will give the impression that there is a positive correlation between the number of people participating in BPJS of Health and the number of people who experience health complaints. This then led to irregularities in the original purpose of establishing the Health BPJS.

Literacy in the financial sector of the Indonesian people is still very minimal, including in terms of literacy in the insurance sector. The benefits received by the community in participating in insurance cannot be felt immediately at that time, but it can be felt when people experience complaints in their health. These things are what make the government have to force it first to make the public aware of the importance of health insurance. The coercion to have health insurance is more extreme by the Australian government which forces its citizens to have health insurance other than government-issued insurance, namely by imposing fines for people who do not have health insurance Connelly and Brown (2008).

The same was done by Vietnam. If Australia requires its residents to have health insurance as adults, Vietnam requires residents to have health insurance since the population is six years old or is in primary school(Cuong, 2011). Thesteps taken by the Australian and Vietnamese governments can be emulated in Indonesia if the call to have BPJS Kesehatan is ignored.

The interesting thing in Indonesia itself is that people will start to realize that they need health insurance when the 
community has experienced a health problem that forces them to carry out routine care and has to pay a lot of money. In this condition, people are just aware and willing to buy insurance, both government health insurance and private health insurance. However, the moral hazard condition in health insurance is very difficult to prove and can take a long time in the proving process (Zhao, 2014).

The variables of the number of hospitals, the number of health centers and government spending in the health sector have no significant effect, but the direction of the relationship is the same as the hypothesis previously described. Thus, the results of this study actually support the provision of basic health facilities and infrastructure. The availability of good health infrastructure can reduce the number of people experiencing health problems. This is indicated by the value of the correlational relationship which is negative. The government only needs to continue and educate the public more massively to use these health facilities, not only when there are complaints about their health, but people can use all these health facilities to be able to understand more about health.

Health treatment is not only curative or curing sufferers from their illnesses, but health care also includes promotive and preventive actions that must also be carried out by the government. These two actions are as important as curative actions. Promotive and preventive actions are more of a preventive nature before an outbreak or the occurrence of diseases that can be more life-threatening. All health management measures should be carried out jointly by all health institutions, even at the lowest level.

Comprehensive health care that includes health services ranging from promotive, preventive and curative is very much needed by the community. The community needs to be educated properly on how to maintain good health. Several previous studies have firmly concluded that there is a positive correlation between the incidence of increasing public welfare and the incidence of cancer. This briefly shows that the lifestyle which is based on current consumptive patterns tends to be carcinogenic.

\section{CONCLUSIONS}

The study came to the conclusion that of all the variables offered, only the number of BPJS participants had a positive and significant effect on the number of people who experienced illness complaints. The results of this study explicitly show the importance of having health insurance for both the public and the government. The community can save on their health expenditures by becoming a BPJS participant and the government is able to better optimize their human resources because the entire community is in a healthy condition.

\section{REFERENCE}

Abbott, A., \& Jones, P. (2020). Government response to increased demand for public services: The cyclicality of government health expenditures in the OECD. European Journal of Political Economy, 101988. https:// doi.org/10.1016/j.ejpoleco.2020. 101988

Agénor, P.-R. (2008). Health and infrastructurein a model of endogenous growth. Journal of Macroeconomics, 30(4), 14071422. https://doi.org/10.1016/j. jmacro.2008.04.003

Aghapour, A. H., Yazdani, M., Jolai, F., \& Mojtahedi, M. (2019). Capacity planning and reconfiguration for disaster-resilient health infrastructure. Journal of Building Engineering, 26, 100853. https://doi. org/10.1016/j.jobe.2019.100853

Bettin, G., \& Sacchi, A. (2020). Health 
spending in Italy: The impact of immigrants. European Journal of Political Economy, 65, 101932. https://doi.org/10.1016/j.ejpoleco. 2020.101932

Connelly, Luke B dan Brown, Shelton, 2008, Lifetime Fairness? Taxes, Subsidies,Age-bAsedPenalties and ThePrice ofPrivateHealthInsurance inAustralia, ACERHWorking Paper no1, June 2008. https://mpra.ub.unimuenchen.de/14671/3/MPRA paper_14671.pdf

Cooper, C. M., \& Wardropper, C. B. (2021). Environmental, public health, and economic development perspectives at a Superfund site:AQ methodology approach. Journal of Environmental Management, 279, 111571. https://doi.org/10.1016/j. jenvman.2020.111571

Fanti, L., \& Gori, L. (2011). Public health spending, old-age productivity and economic growth: Chaotic cycles under perfect foresight. Journal of Economic Behavior \& Organization, 78(1-2), 137-151. https://doi.org/ 10.1016/j.jebo.2010.12.014

Giang Thanh Long, 2008, Social Health Insurancein Vietnam; Currentlssues and Policy Recommendations, Series SocialSecurity Initiativesin East Asia, International Labour Organization, https://mpra.ub.unimuenchen.de/9926/1/MPRA paper_9926.pdf

Gupta, M. R., \& Barman, T. R. (2010). Health, infrastructure, environment and endogenous growth. Journal of Macroeconomics, 32(2), 657-673. https://doi.org/10.1016/j.jmacro. 2009.09.001

Joshi, G., Rautela, P., Ghildiyal, S., \& Chauhan, R. (2020). Assessment of seismic vulnerability of health infrastructure in Uttarakhand: An earthquake prone Himalayan province of India. International
Journal of Disaster Risk Reduction, 46, 101506. https://doi.org/10. 1016/j.ijdrr.2020.101506

Kruse, I., Pradhan, M., \& Sparrow, R. (2012). Marginal benefit incidence of public health spending: Evidence from Indonesian sub-national data. Journal of Health Economics, 31(1), 147-157. https://doi.org/10.1016/j. jhealeco.2011.09.003

Sanjaya, M Ryan, 2007, Health Cost in Indonesia: Evidances From IFLS and Susenas Data, Jurnal Ekonomi danBisnis FEBUGM, Januari2007, https://mpra.ub.uni-muenchen. de/13986/1/MPRA_paper 13986.pdf

Sattler, S., Gignac, J., Collingsworth, J., Clemmer, S., \& Garcia, P. (2018). Achieving a clean energy transition inIllinois:Economicandpublichealth benefits of replacing coal plants in Illinois with local clean energy alternatives. The Electricity Journal, 31(10), 52-59. https://doi.org/10. 1016/j.tej.2018.11.001

Schünemann, J., Strulik, H., \& Trimborn, T. (2017). Going from bad to worse: Adaptation to poor health health spending, longevity, and the value of life. Journal of Economic Behavior \& Organization, 140, 130-146. https://doi.org/10.1016/j.jebo. 2017.02.018

Tambo,E., Khayeka-Wandabwa,C., Muchiri, G. W., Liu, Y.-N., Tang, S., \& Zhou, X.-N. (2019). China's Belt and Road Initiative: Incorporating public health measures toward global economic growthand shared prosperity. Global Health Journal, 3(2), 46-49. https:// doi.org/10.1016/j.glohj.2019. 06.003

Zhao, K. (2014). Social security and the rise in health spending. Journal of MonetaryEconomics, 64,21-37. https://doi.org/10.1016/j.jmoneco. 2014.02.005 